\title{
Advanced Automated Manufacturing for Timber-based Panelised Wall Systems
}

\author{
Kristopher Orlowski* \\ Center for Advance Manufacturing of Prefabricated Housing, \\ The University of Melbourne, Melbourne 3010, Australia. \\ *Correspondence: kristopher.orlowski@ unimelb.edu.au; Tel.: +61-490-001-356
}

\begin{abstract}
The advanced manufacturing of fully prefabricated timber-based walls for panelised buildings is explored to provide a comprehensive view of developed knowledge and leading industry practice in terms of automation. Information sourced from leading automation companies, manufactures, prefabricators and literature were used to fully outline the automation for each respective process in prefabricated timber construction. An outcome of this work is an understanding of the current standing and trend in automation of processes in panelised prefabrication around the world. This paper presents the systems from leading automated machinery manufacturers in prefabrication that can be utilised in different processes within the prefabrication of timber-based panelised walls. It is evident in the research that certain manufacturing processes in timber-based panelised prefabrication are more suitable for automated technologies which is also controlled by the local context. There are a number of automated technological solutions which are capable of conducting several key processes required for timber-based panelised, however very few offer a fully automated production line. By analysing relevant automated systems, a combination of the most efficient technological solutions for each process can be considered for new or to be upgraded production lines which are suitable for panelised prefabrication of timber-based walls. Ultimately, this work creates the platform for further academic study and development in the under explored areas of automation in timber-based prefabricated panelised construction processes.
\end{abstract}

Keywords: Automation, Manufacturing, Prefabrication, Panelised buildings, Timber-based walls

\section{Introduction}

\subsection{Background}

Currently, many companies utilise and adopt conventional construction techniques for wood based prefabricated manufacturing [1]. However, timber-based prefabricated panels are an increasingly popular and utilised system in the construction industry and with it the automated technologies which support them are currently being strongly developed and adopted in replacement of conventional methods $[2,3]$. There are many materials used for the structural system such as wood, steel and concrete 
each having their own benefits and should be used according to the desired projects and governing requirements. The manufacturing of prefabricated timber panel walls is an increasingly developing field where a combination of automated and manual processes are utilised to assemble an efficient production line [4]. Recently, there has been an increasing trend in the construction of timber structures [5]. Due to this, it is essential that the manufacturing processes are able to withstand the increase in demand and also satisfy the relevant standards and quality assurance. The timber products industry is significantly behind the level of automation in other industries, particularly in comparison to the automotive industry [6]. Thus, significantly more work is needed in the understanding and development of automated technologies for the timber products industry [7].

The construction of a timber-based fully prefabricated panelised walls includes a variety of different segments assembled through numerous stations along a production line. Each station is responsible for a specific function that will contribute to the overall quality and productivity of the assembly line. In recent years the processes involved in each station are increasingly becoming met by automated solutions with the primary hinderance being missing knowledge of possibilities and so many more opportunities exist for development and adoption in this area [3, 8]. Companies involved with the full prefabrication of timber-based walls have a variety of inclusions for assembly which have the potential to be automated, the main parts include the sheathing, studs, glazing, doors and openings, services, insulation, building wrap and the façade.

The respective manufacturing plants are large in nature and located off site close to transportation routes and have easy access for movement of materials into the factory and finished products out to site [5]. The assembly lines of many facilities involve or even based upon carefully controlled manual labourbased tasks. Since many processes in manufacturing of panelised walls is repetitive, machines are well equipped to efficiently and accurately processes high capacity of materials. Therefore, this can potentially increase the production capacity, reduce production time and increase the accuracy and quality throughout the assembly line $[9,10]$. Furthermore, in the accuracy of conventional cutting and sawing of the timber panels, there is a higher chance of human error as tedious tasks such as measuring and cutting a piece of wood exactly is comparatively unreliable when conducted by humans. Automated machines refer to computer-aided design software, which specifies the exact dimensions to cut and assemble the materials. Because of this, a seamless and controllable process, without any interruptions, can be formed and customised without the risk of human error in manufacturing [11]. In addition to this, advanced automated machines can not only reduce the amount of labour needed but also the training required as workers can oversee machines rather than operate them [9]. As a result, this may decrease the reliance of construction companies on skilled labour and provide a solution to the current shortage in construction workers in the manufacturing field $[12,13]$. 


\subsection{Purpose}

The purpose of this work is to explore the current and emerging processes within the automated manufacturing of prefabricated timber-based walls for panelised buildings. As a result, a comprehensive view of the current knowledge and leading industry practice in terms of automation is presented. This will aid the selection and development of an automated solutions that are an alternative to labour-based manufacturing techniques in the context of timber-based panelised prefabricated construction. Ultimately, this work creates the platform for further academic study and development in the under explored areas of automation in timber-based prefabricated panelised construction processes.

\section{Advanced manufacturing for timber-based panelised construction}

Traditionally, timber-based wall prefabrication is limited to the structural frame and no more however in recent years a greater number of processes have been included into the premanufacturing for essentially fully complete walls. For example, the inclusion of façade, windows and glazing, insulation and even the weatherproofing $[14,15]$. This is to more closely achieve what's termed a fully prefabricated wall which can be placed and connected on site with no more work to be done. The construction of a timber-based fully prefabricated panelised walls include a variety of different segments assembled through numerous stations along a production line. Each station is responsible for a specific function that will contribute to the overall quality and productivity of the assembly line. In recent years the processes involved in each station are increasingly becoming met by automated solutions. Typically, one of the first stations that is integrated in the production line with a automated solution is the sawing and cutting station which is essentially designed to cut timber blocks and panels into specific shapes and sizes that will be utilized to construct the panel [16]. These machines are Computer Numerical Controlled (CNC) and are able to process large amount of timber a day working on a 4 or 5 axis saw unit and multiple tools to easily cut and process the panels straight from the specified design. The framing and studding station then constructs the basic structural system of the panel, aligning the timber edges to the specific design and attaching them all together using manually or automated technology $[17,18,19]$. In addition, insulation is added into the timber panels to provide thermal insulation. A new automated system by Weinmann named blowTec installs insulation with a blow-in plate attached to an automated multifunctional bridge [20]. Another insulation installation method includes the Val-UTherm, where the insulation material is injected into a closed timber panel and expands within it [21]. A multifunctional bridge is an alternative to having many different stations conducting processes and adding elements to timber panel. This machine is fully automatic and can be fitted with different processes to add multiple features into the panel in one station such as cutting, nailing, stapling and gluing. 
To better ensure the timber panels are weatherproof a building wrap also known as a membrane, is applied at the interface between the structural system and the façade as a secondary measure to stop any outside rain yet allows for vapour transfer to help prevent condensation [22]. The wrap is usually a membrane or perforated material that is nailed onto the timber frame [22]. Companies such as CCG Ltd, Island exterior fabrications and Baufritz are currently some of the known providers and users in advanced panel wrap technology [22, 23, 24].

A buffer station is originally purposed as a transportation platform that would move elements of the panel from one station to another, particularly when one process is vulnerable to delays to which the buffer station would absorb. However, to fully maximise the potential of a buffer table, an assembly lines can utilise this station for work checks such as quality assurance or alignment markings. Furthermore, a buffer station will need to be in sync with the assembly line layout and therefore may have to be able to transport the products in a 3-directional movement, that is lengthways, width ways and vertically [25].

Turning stations are essential in a timber panel assembly line to facilitate work and quality assurance checks on both sides of the timber panel. A common manual process of hooking the panel to an overhead gantry crane and lifting may be economical when this is already existing to a factory however less time efficient to new purpose specific and automated solutions. Systems such as the Randek butterfly turning table BS40 are now widely used in advanced assembly lines, it has two tables that elevate at an angle allowing the panel to be flipped accurately and safely [26]. An alternative is the Vacustand VS-180E supplied by a vacuum technology handling specialist named Fezer, which can turn a panel in 20 seconds by forming a vacuum onto the panel providing suction to hold the panel [27].

An intelligent storage system for both raw materials as well as finished products is essential for the manufacturer to improve efficiency and remain competitive. They optimize the material management by reducing wasted scraps and minimizing redundant search time. Horizontal storage techniques are widely used in many companies where the timber panels are stored horizontal according to their purpose. As a result, they can be easily identified and transported onto the assembly for further work when needed [28]. HOMAG, Hundegger and CSR provide horizontal storage systems. Vertical storage systems on the other hand stack timber panels on the face allowing panel elements to be easily shifted to the storage and retrieved for return to the manufacturing process [29]. Weinmann WLV/WLW storage technology is a leader in this field and includes a swivelling top guide on overhead crane cross rails for automatic element positioning and pick up, loading carriage and standing wall trolley on roller conveyers [30].

The efficiency and productivity of a manufacturing assembly line however does not solely rely upon the machines and manufacturing processes. Management techniques provide a fundamental element to the assembly line that when managed well can reduce costs and increase capacity significantly [31]. An 
example of this is Kanban which is an inventory control system that manages the supply chain in a manufacturing plant [32].

The strength of a building relies heavily upon the transfer of load from one connection to another. A solid and reliable connection method must be quick and easy to be fitted on site while being utilized to increase the strength of timber panel and enable the structure to withhold an excessive amount of stress. In timber buildings, an effective connection provides the building with strength, stiffness, stability and ductility [33]. Pryda, a timber and connections company, provide a number of different premade connections such as the connector plate and knuckle nail plate fitted with pre-fitted nails that can be nailed onto each timber structure to form a stable connection. The heavy pre-punched plate however will be able to handle a heavier load as the plate is thicker and wider. Prefabricated connections such as the Sherpa dovetail connection provide a balance of durability and strength as the forces are transferred perpendicularly to the connection direction. This connection works as two plates are pre-installed into each face of the wooden panel, nails and then drilled through each connection to reinforce the connection and the plates are then interlocked with each other [34].

\section{Processes and their automation}

Manufacturing and construction of components as input for onsite use in buildings has increased over time and with it the complexity and number of processes involved. Furthermore, the method of prefabricating panelised systems which now encompass much more than just the structural frames has been greatly shifted from efficient manual labour in repeatable and controlled processes to semi and fully automated processes. The latest of which have been identified, studied and are presented below for further development and adoption.

\subsection{Cutting and sawing}

\subsubsection{Hundegger}

Hundegger has developed the Speed Panel machine SPM-2 which is specifically designed for the cutting and sawing of wall panels. SPM-2 is fully automatic and only requires one person to operate it using the supplied purpose specific computer software. Wood, engineered timber panels and other panels can be cut by this machine such as solid wood, Orientated Strand Board (OSB), chipboard, plywood, plasterboard, fibre cement, and soft fibreboard [16]. The machine is programmed to optimise the use of all materials when cutting. Stacks of raw timber board are picked up by a forklift and supplied to the machine in bulk, which is the only stage where labour is involved. The panels are automatically fed into the process centre for cutting. The machine has been designed to read CAD files, which most design drawings can be converted to, no extra editing or programming is needed during the manufacturing process. After the process is finished, the machine automatically stacks the finished product on the 
output side. In addition, the machine can also suit the needs for artistic and architectural purposes such as some decorative interior parts and façade. Processing units can be customised to best suit the purpose required by the end user. Universal circular sawing and milling units have two options which are 4-axis and 5-axis saw unit. A smaller 5-axis saw unit can be tilted by 50 degrees which is useful when carving facades or interior parts [16].

\subsection{Framing and Stud Fitting}

\subsubsection{Semi-automated stud fitting}

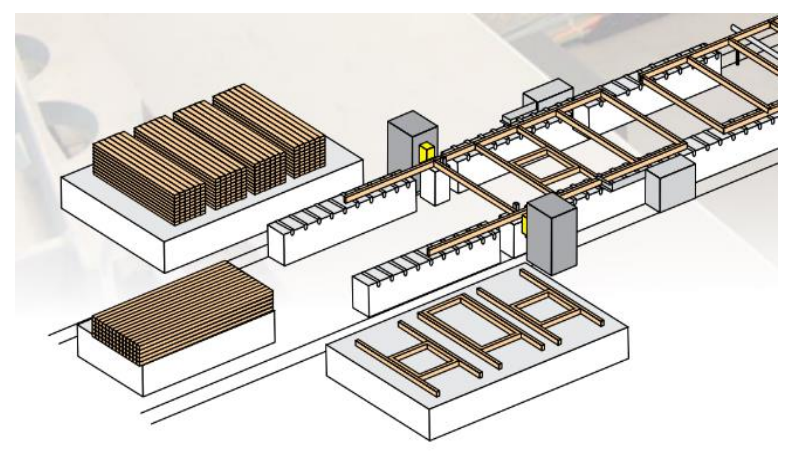

Figure 1. Weinmann framing station; WEM 100 [16].

Weinmann has created the WEM 100 which is a semi-automated framing machine in which the studs are manually fed in. Afterwards, the discharge gripper moves along for a given distance. The next stud is fitted in, aligned and nailed automatically, and the process will continue to the following studs. This is a convenient starting model for smaller companies that with a production capacity of 100 and more houses annually [35]. There are optional supplementary modules including a noggin station and automatic stud feeding. Studs positioning and clamping of the framework are fully automatic and there is no need for manual measuring and marking, assuring speed and permanent high quality. The framing station produced are in accordance with batch sizes, which can offer a customer-tailored production [36].

\subsubsection{Automatic stud fitting}

\subsubsection{Weinmann framing station WEM 250}

The WEM 250 model is similar to the WEM 100, but additionally equipped with a fully automated stud assembly system. The studs are fed and positioned automatically by a feeding portal. The feeding portal takes studs from different stacks to roller conveyor. After that, the studs are transported to stud assembly table and assembled into the frame in a fully automatic process. The average speed can be up to $2 \mathrm{~m}$ per minute. Based on this operation speed, the production size can be up to 1000 houses per year, depending on the type of frames [36]. 


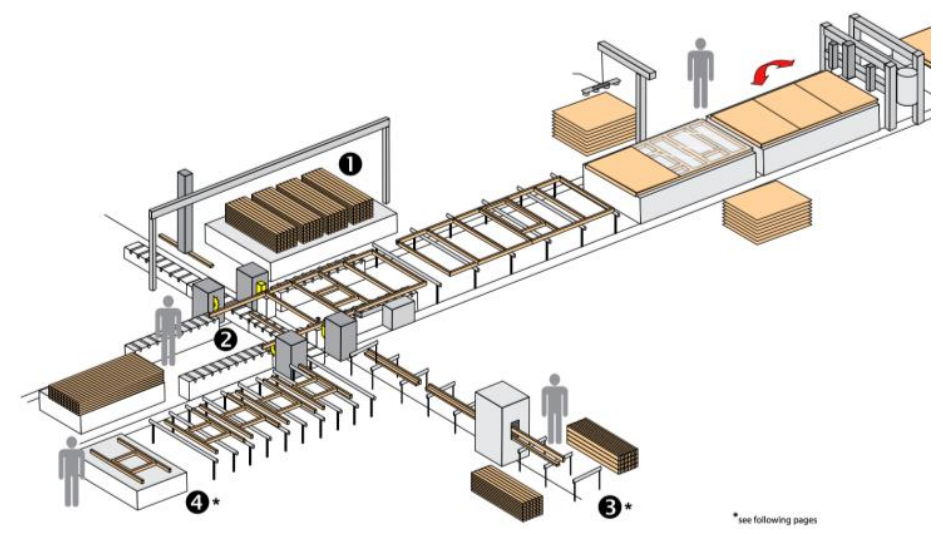

Figure 2. Weinmann framing station; WEM 250 [16].

\subsubsection{Randek Framing Station}

Randek framing station as shown in Figure 3 is automatically set-up according to the corresponding CAD drawing data. Grippers clamp and separate the top and bottom timber plates for a controlled placement of studs. The studs are fitted automatically by a stud feeder to the framework. Afterwards, sub components are lifted into the production line. The frame is nailed automatically according to the drawing and reserved holes drilled on the top and bottom plates [37].

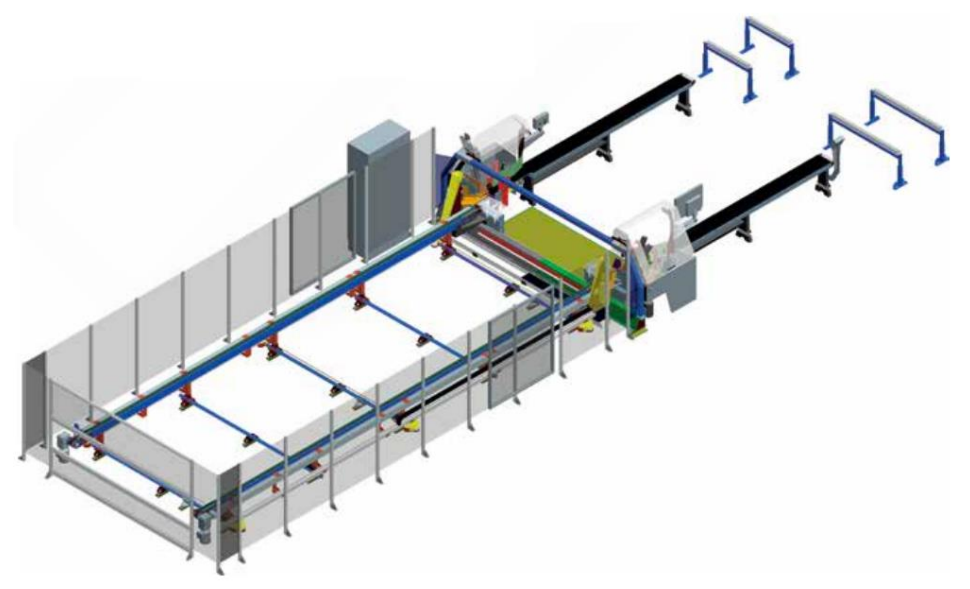

Figure 3. Randek framing station [17].

\subsubsection{Noggin assembly station}

The noggin assembly station is a support station for the assembly of short longitudinal studs, also known as noggins, which give the frame some lateral stability and minimizes the deflection of the internal plasterboard. The station is manually movable on linear guides and is located in between the framing stations and the transfer station [36].

\subsubsection{MBA Automatic Timber Frame Assembly Station}

This assembly station provides an automatic squaring and nailing station for heavy duty timber panel manufacturing. During assembly and nailing of studs in the station, panels is held secure and square. One operator is needed to manually position studs and the sub components for the panel. The operator 
can stand in the centre of the panel and move along with stud fitting. Only this one operator is needed to operate this assembly station.

The stud and sub components are located based on the automatic positioning by locating robot arms. The panel is assembled automatically one step at a time. Meanwhile, the on-board CNC unit also controls the operation of nailing and movement of locating arms. However, onsite an operator can override the automatic sequence and can insert difficult or priority frames and then return to automatic sequencing [19].

\subsection{Multi-functional bridge}

Multi-functional bridge is an innovative solution for the manufacturing of offsite timber panels in a time and cost-efficient manner. It is a durable machine that does a combination of processes during manufacturing of wall panels.

\subsubsection{Weinmann}

The WMS product line consists of fully automatic multi-functional bridges designed for various purposes in either small, medium-size or large prefab manufacturing companies [20]. The system is very flexible depending on the enterprise size and how many processes they want to automate. CCG a leading prefabricator in this field has adopted this system and appreciated the efficiency and economic benefits it brought [38]. The velocity system developed by CSR, a leading building products company in Australia, is also successfully manufacturing wall panels based on Weinmann's multi-functional bridge [28]. The most advanced model is capable of fastening, nailing, stapling, gluing, plastering, cutting and sawing all in one station as shown in Figure 4. There is wide product range of models and its technical data for the manufacture of panels as shown in Table 1. Sandwich panels can be easily cut by WMS 160 Structurally Insulated Panel (SIP) machine and the WMS170 can glue and fasten plaster. Assembling of the timber frame manually or via a semi-automated or fully automated framing station is required prior to being moved to the station with the multifunctional bridge. The bridge fastens the sheathing to the frame itself where the nailing of the sheathing board is then done completely automatically. Windows and doors can be then automatically cut out per the CAD drawings read by the given computer software. If the insulation blowTEC system is purchased, it could also be attached to the bridge. The multi-functional bridge can automate many of the process of panel manufacturing however with the significant drawback that it will because the key bottleneck in the assembly line which will limit production capacity to the sum total of the time of the processes chosen for the multifunctional bridge. The maximum product dimension the WMS series is capable of processing is $3200 \mathrm{~mm}$ wide by $50 \mathrm{~m}$ long by $500 \mathrm{~mm}$ deep. 


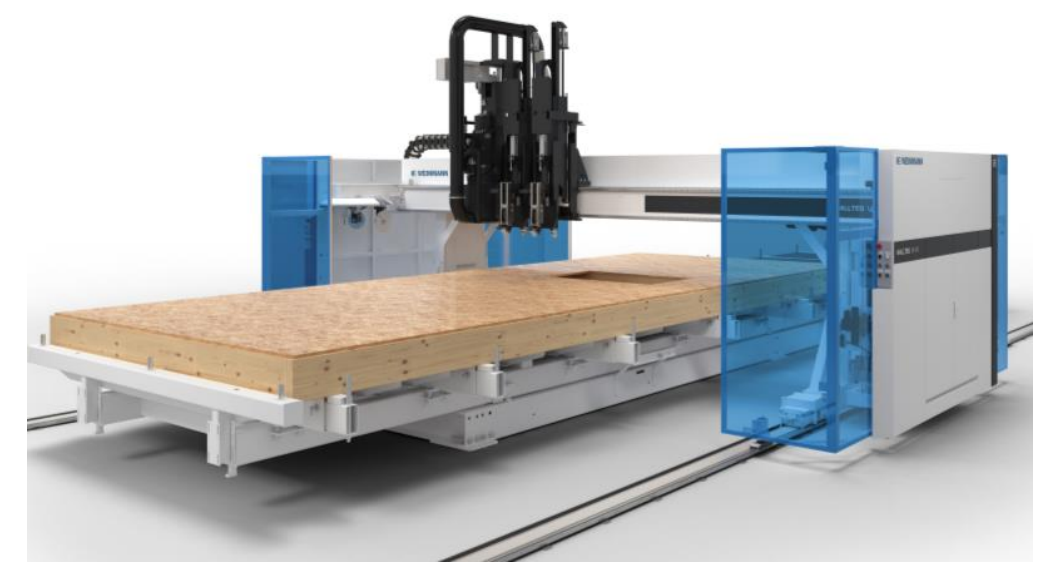

Figure 4. Weinmann multi-functional bridge [38].

Table 1. Technical data of the various machine models [38].

\begin{tabular}{|c|c|c|c|c|c|c|}
\hline & WMS100 & WMS110 & WMS120 & WMS150 & WMS160 & WMS170 \\
\hline $\begin{array}{c}\text { Brief } \\
\text { Description }\end{array}$ & $\begin{array}{l}\text { Machine for } \\
\text { standard } \\
\text { requirement of } \\
\text { fastening and } \\
\text { processing }\end{array}$ & $\begin{array}{l}\text { The fastest } \\
\text { machine for } \\
\text { fastening }\end{array}$ & $\begin{array}{l}\text { The most } \\
\text { flexible } \\
\text { machine, } \\
\text { equipped with } \\
\text { tool changer }\end{array}$ & $\begin{array}{l}\text { Can be } \\
\text { expanded with } \\
\text { up to } 6 \\
\text { aggregates for } \\
\text { parallel } \\
\text { processing. } \\
\text { Such as } \\
\text { fastening and } \\
\text { processing }\end{array}$ & $\begin{array}{l}\text { Specialist } \\
\text { version for the } \\
\text { processing of } \\
\text { sandwich } \\
\text { panels }\end{array}$ & $\begin{array}{l}\text { Equipped for } \\
\text { use as a } \\
\text { plastering } \\
\text { bridge in the } \\
\text { application of } \\
\text { adhesive and } \\
\text { plaster }\end{array}$ \\
\hline $\begin{array}{l}\text { Highlighted } \\
\text { Functions }\end{array}$ & $\begin{array}{l}2 \text { aggregate } \\
\text { carriers }\end{array}$ & $\begin{array}{l}\text { Parallel } \\
\text { nailing with } 2 \\
\text { fastening } \\
\text { devices }\end{array}$ & $\begin{array}{l}12 \text { tools with } \\
\text { spindle and } \\
\text { carrier for } \\
\text { fastening tools }\end{array}$ & $\begin{array}{l}\text { Up to } 6 \text { freely } \\
\text { available units }\end{array}$ & $\begin{array}{l}\text { 12-fold tool } \\
\text { changer, } 20 \\
\mathrm{~kW} \text { spindle } \\
\text { and special } \\
\text { extraction }\end{array}$ & $\begin{array}{l}\text { Aggregate unit } \\
\text { to mount a } \\
\text { spray nozzle }\end{array}$ \\
\hline $\begin{array}{l}\text { Technical } \\
\text { Data }\end{array}$ & $\begin{array}{l}\text { Stapling up to } \\
10 \text { staples/sec. } \\
\text { Sawing up to } \\
30 \mathrm{~m} / \mathrm{min} \text {. } \\
\text { Nailing up to } \\
8 \text { nails } / \mathrm{sec} \text {. } \\
\text { Milling up to } \\
25 \mathrm{~m} / \mathrm{sec} \text {. }\end{array}$ & $\begin{array}{l}\text { Parallel } \\
\text { nailing } \\
\text { resulting in } \\
\text { twice the } \\
\text { nailing speed }\end{array}$ & $\begin{array}{l}\text { Sawing up to } \\
350 \mathrm{~mm} \text { depth }\end{array}$ & $\begin{array}{l}\text { Placement of } \\
\text { sheathing and } \\
\text { battens from a } \\
\text { min. } 24 \times 48 \\
\text { mm to max. } \\
60 \times 150 \mathrm{~mm}\end{array}$ & $\begin{array}{l}\text { 5-axis chain } \\
\text { saw for } \\
\text { diagonal and } \\
\text { straight cut up } \\
\text { to } 350 \mathrm{~mm} \\
\text { depth }\end{array}$ & $\begin{array}{l}\text { Speed is } \\
\text { dependent on } \\
\text { panel size and } \\
\text { thickness of } \\
\text { plastering } \\
\text { material }\end{array}$ \\
\hline
\end{tabular}

\subsubsection{Randek}

The NB3000F is considered as the multi-functional bridge produced by Randek for this construction context as it is equipped with 4 comprehensive tools to maximise the capacity [39]. The building company Strongbuild have adopted the system and delivered several projects with high quality finishes [40]. Four units that are included in the bridge are: milling units, drilling units, saw unit and stud aligner. The production process requires CAD-files to be prepared beforehand. By placing both the top and bottom chord onto the production table, the stud can be placed manually, the stud aligner will make sure they are at the location where it's designed on CAD drawings precisely. The sheathing can then be attached for nailing, sawing and drilling. The saw unit can cut windows and doors slot on wall panels up to $300 \mathrm{~mm}$ in thickness. The unit can be interpolated in case special cuts such as angled cuts if required. 
The drilling unit allow the service rough-in to be achieve by automatically drill holes for electricity and water lines.

\subsubsection{MBA MOBI-One}

MOBI-One is an assembly machine for timber frame panel walls designed by MBA. It is a complete working station to produce timber panel walls with one operator in a semi-automated manner. Studs are driven by a servo drive motor to its required position and picked up by the operator. The operator will fit the stud into the reserved places and the stud will be nailed automatically [18]. Depending on the requirements for production, nailing bridges can be either mounted over a single table, or floor mounted to travel over several tables. A fully automatic nailing station for nailing in accordance with the design specifications includes the following functions: nailing or stapling of sheathing, routing of openings or overhang, application of breather membrane and nailing or stapling of battens.

\subsection{Window assembly}

Generally, the windows assembly is contacted separate from the main production line but ideally at the same facility in order to balance space and management requirements then fed into the main line prior to the façade station.

\subsubsection{Soukup Window Assembling Production Line}

\subsubsection{Assembling Table KS2400}

This process uses an assembling table for cutting and mounting perimeter boards and cutting glazing beads. This table is fitted with pneumatic scissors and a hand mitre saw and relied on human labour. For long parts, containers are graded in depth for fitting in the table; for small parts, there are pockets and wood screw for fitting [41].

\subsubsection{Mounting and Glazing Stand GW2500}

This process offers a vertical stand for windows in assembling, adjustment and testing. GW2500 is equipped with a fixed shoulder and a movable shoulder that has a pneumatic piston. For the fixed shoulder, it can be opened for an easy uploading to conveyor. Meanwhile, the whole frame can rise to $500 \mathrm{~mm}$ maximum for easy mounting and glazing installation [42].

\subsubsection{Window Finishing}

A consecutive series containing an impregnation coating tank, spraying booth and overhead conveyor make up the window finishes production line. Impregnation tank is for basic coating of window elements or frames. Spraying booth is equipped with cardboard on outside and textile filter on inside. It provides a dry spraying box for removal from working area. Overhead conveyor is designed for window frames that finished and hanged up. Window frames will be transported to the assembling areas. 


\subsubsection{MBA Window Assembly Table}

MBA window assembly table is a station designed for windows in the pre-fitting of sub-assemblies. Afterwards, windows will be placed into the main wall assembly [17].

The table is manually opened and closed by hand via a wheel crank and linear guide. A rack and pinion control the adjustable range of $500 \mathrm{~mm}$ to $2400 \mathrm{~mm}$. The maximum subassembly length is $2700 \mathrm{~mm}$. There are side clamps that ensure squareness of frames and support for lateral studs.

\subsubsection{Installation and weather-stripping of windows}

Window installation is the last process of the manufacturing before transporting or storage of timber panel. In most cases, window installation is semi-automated with a window holder helping to move the assembly to a suitable position for fitting. Afterwards, the windows will be weather-stripped with certified mastics, vapour barrier tapes, expandable sealants and caulking as necessary.

\subsection{Insulation}

\subsubsection{Weinmann}

Weinmann offers a system called blowTEC to install insulation in a fully automatic way by attaching the insulation blow-in plate to a multi-functional bridge [20]. However, if a multifunctional bridge is not used or if it is not compatible then the blow-in plate can be connected to an overhead gantry crane to operate via manual control. Various insulation materials from two key suppliers Isocell and Gutex are recommended to be chosen for cross compatibility the exact selection of which will depend on the client's demand [43]. The insulation materials provided are eco-friendly and use of natural materials such as cellulose and word fibre, they are CO2-nuetral and can be easily composted at the end of the usage cycle. The location and volume of the insulation is very precise due to the nature of the blow in method and as it is pre-designed and controlled via CAD files automatically via a supplied interface. The insulation material will be blowed into the framework at the correct locations automatically by the system as shown in Figure 5. The interface displays the volume of insulation in each slot after it has been blown as a quality control measure. The technical data of blowTEC capabilities is shown in Table 2 which is significantly beyond a human's capacity which would require measuring, cutting and fitting. Weinmann's managing director Hansbert Ott has claimed through a case study that the use of this system could not only compensates for the running costs and material costs but also allow for further savings by conducting a profitability calculation. It was found that in some cases a profit can be made in manufacturing a total of 30 houses or more through this systems adoption [20]. 


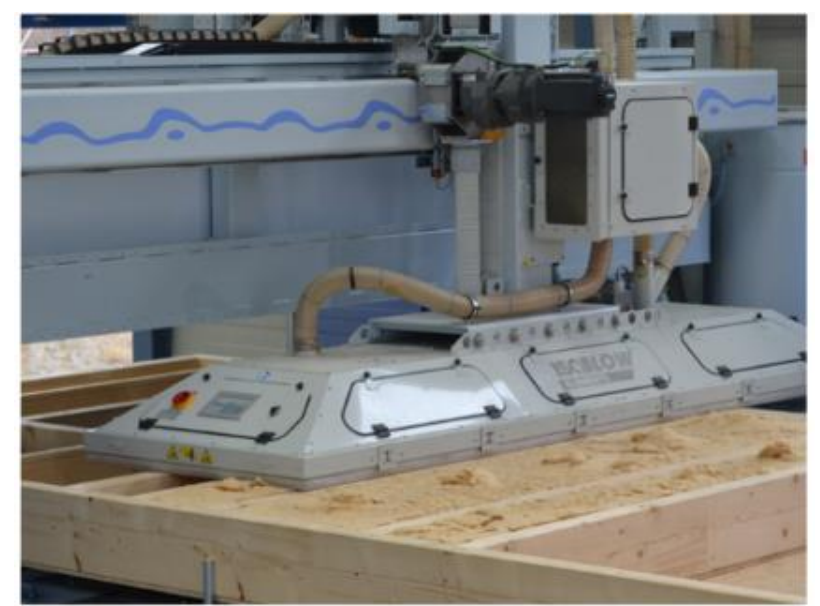

Figure 5. BlowTEC plate blowing insulation [20].

Table 2. Technical data of BlowTEC [20].

\begin{tabular}{|c|c|c|}
\hline Capability & Value & Units \\
\hline Max. element width & 3200 (optional 4200) & $\mathrm{mm}$ \\
\hline Max. element depth & 500 & $\mathrm{~mm}$ \\
\hline Max. element length & 5 & $\mathrm{~m}$ \\
\hline Blow-in power & approx. 1.000 & $\mathrm{~kg} / \mathrm{hour}$ \\
\hline Production capacity per standard wall* & 20 & $\mathrm{~m} / \mathrm{min}$ \\
\hline
\end{tabular}

*Standard wall considered to be $2.7 \mathrm{~m}$ high and $0.2 \mathrm{~m}$ thick

\subsubsection{Val-U-Therm}

The foam insulation injection technique by Val-U-Therm installs insulation in a semi-automatic way with high quality product. The timber frame manufacturing company Scotframe is using this advanced technology to provide closed panels with high thermal performance [44]. Since the insulation is injected into the closed panel, there aren't various choice of materials for selection, and only expandable polymer is currently used. In terms of the environmental and sustainability credentials, the insulation is considered bio-based, parts of it are extracted from the recycled and renewable vegetable oil [21]. High pressure technology is applied to the machine when injecting insulation which fills every cubic millimetre of the central space within each gap. For best efficiency multiple walls can be stacked horizontally prior to beginning injection. Two holes need to be drilled on the top and bottom plate at each stud gap for injection. To ensure the insulation does not leak out, a press machine-applies a load onto the stack. The insulation is then injected from the top plate of the wall panel, when the gap has been filled up, overflow of the insulation will occur from the other side. This insulation fitting in this manner generates practically no wastage with maximum fill since there are no offcuts and no voids.

\subsubsection{Randek}

Randek is an experienced Swedish company in supplying machinery for prefabricated construction since 1940s and have automated the insulation installation process in their own way through adopting preexpanded insulation panels. The insulation handling system as shown in Figure 6 which conducts the process of transport, de-packing, cutting, gluing and feeding fully automatically with zero labour required [37]. The system is installed above the normal production line which saves extensive space in 
the factory. It has a transport conveyor that is connected directly to the outside of factory. When the lumps of insulation have arrived outside the factory, no manual de-packing or forklift transporting is required which prevents double handling and satisfies lean manufacturing principles. The system automatically picks the insulation, cuts it into pieces of the right dimension with minimum waste and applies glue on it. The system will automatically feed the glued insulation into the framing station at the exact right time and location between the studs.

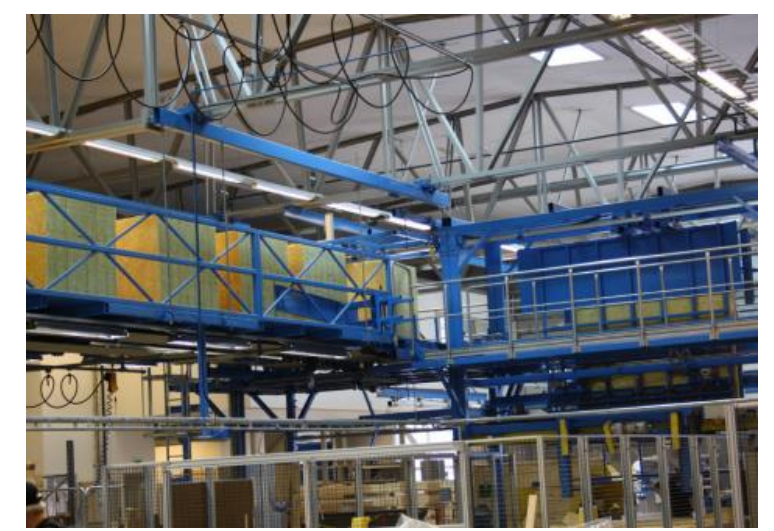

Figure 6. Insulation handling system [37].

\subsection{Building wrap}

\subsubsection{Randek - Membrane cutting station}

Randeks membrane cutting station automatically feeds and cuts the building wrap to the desired length based on CAD or manually imported data [45]. The equipment consists of two rolls of membrane, which enables easy switch to a different roll as shown in Figure 7 . An operator needs to position the wrap and manually staple it to the wall panel or use it in conjunction with a multifunctional bridge.

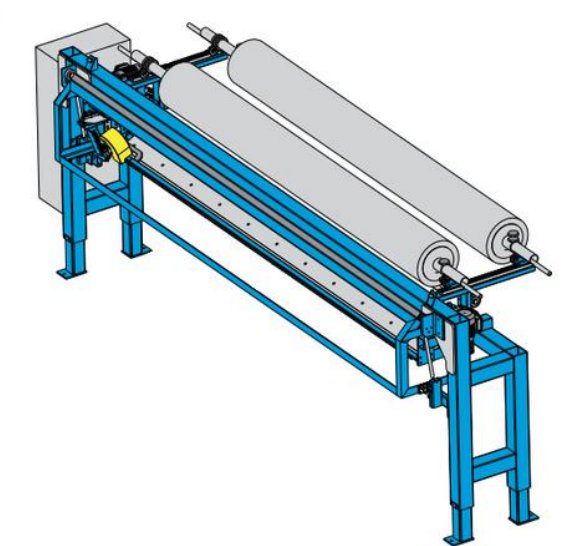

Figure 7. Membrane cutting station [45].

\subsubsection{CCG}

CCG (Scotland) Ltd, one of the main manufacturer of open and closed panel for the off-site construction in UK, has semi-automated production line in the manufacturing facility that comprises of 3 lanes [22]. CCG installs two layer of membrane in the panel production process. The external breather membrane 
is manually applied after the sheathing fitting, where in lane 2 the internal airtight layer is placed after the insulation and boarding station. Both processes are completed manually on a horizontal table.

\subsection{Façade installation}

For most prefabricated panel manufacturers, façade assembly is the last step in the production line before the finished element is packed for transportation. There is a wide range of material that can be applied to the cladding, such as wood, masonry, metal, terracotta, stone or composite materials.

\subsubsection{ISLAND Exterior Fabricators}

ISLAND is a New York exterior fabrication specialist and who amongst other things have established a unitised rainscreen façade system [23]. A number of typical façade materials can be chosen including masonry, these are installed while the panels are orientated horizontally. The workflow is prioritised in materials coming to a stationary panel instead of assembly line with different processing stations. The manufacturing method is manual although highly controlled and can easily integrate into most assembly lines. Additionally, this type of method is compatible with virtually any façade product which may not be the case in automated solutions which may have limitation due to their methods of handling and fastening.

\subsubsection{CCG}

The installation of facades is taking place in the final lane of the manufacturing process at CCG facility [22]. Panels are vertically stored on the distribution trolley, after windows and external doors are installed, external cladding of the wall is manually completed in a controlled environment.

\subsubsection{CSR}

The velocity system developed by CSR has done cladding using Hebel autoclaved aerated concrete and fibre cement products [46]. Further cladding products such as brick works are performed on site. The production \& engineering manager at CSR, Ben McDonough points out the difficulty with off-site cladding is maintaining high level of accuracy (ideally $+/-1-2 \mathrm{~mm}$ ), as well as minimising damage during transport, handling and installation, particularly for cladding products that are heavy and fragile [28]. Therefore, McDonough suggests to better focus on a 'ready to be clad on site' wall system for panelised construction.

\subsubsection{Randek clad nailing bridge NBC3000}

The nailing bridge NBC3000 from Randek is specially designed for automatic nailing of wooden cladding onto wall panels. The bridge contains 8 nailing pushers positioned in parallel with 4 toll wagons as shown in Figure 8. After a wall element is fed into the station, the timber is placed on an adjustable cladding template. During the nail pushing, a batten straightener is used to hold the cladding to ensure the exact position and depth of the nailing work [37]. The automated nail pushing offers high precision and efficient cladding process compared to the traditional nailing method. 


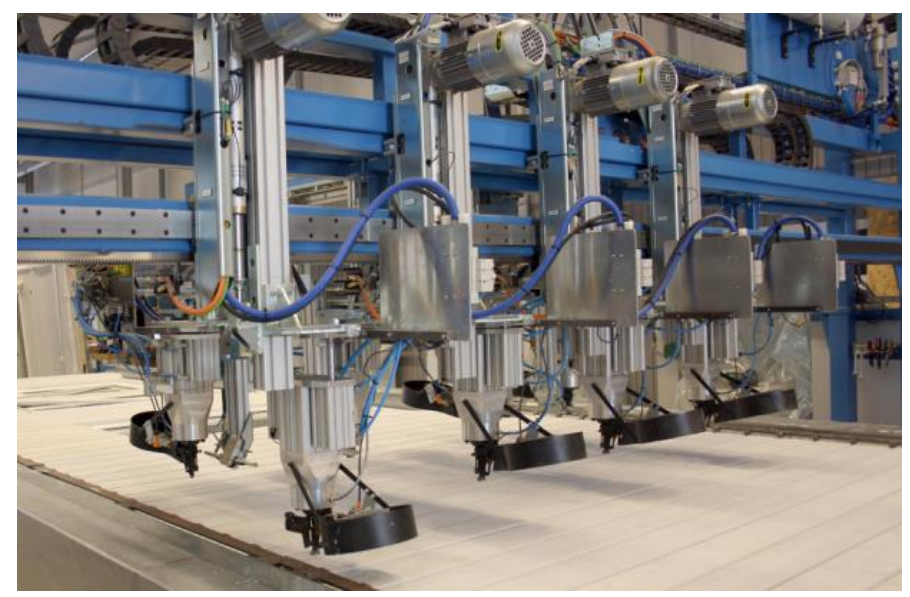

Figure 8. Randek nailing bridge NBC [37].

\subsubsection{HOLZMA HPP 300 multiTec}

The HPP 300 multiTec is a fully automatic machine that contains three functions suitable for façade processing: sawing, drilling and routing. The machinery produces elements that are ready to be installed without the need for manually drilling holes for installation, which makes it ideal for factories manufacturing façade and partition walls. The automatic drilling saves the cost up to $60 \%$ compared to the conventional processes, not to mention the benefit of accelerating the assembly time of facades. The machine is suitable to deal with a wide range of materials for façade production; this includes most of wood-based and plastic materials, as well as gypsum and other composite materials such as fibre cement, HPL and Aluconond [47]. The drilling capacity of HPP 300 multiTec is up to $45 \mathrm{~m} / \mathrm{min}$ whereas the sawing speed is up to $90 \mathrm{~m} / \mathrm{min}$ [47].

\subsection{Storage / handling system}

To optimise the material management, it is vital to reduce material wastage through use of appropriately sized raw products and minimising search and retrieval time. An intelligent storage system for both raw materials as well as finished products is essential for the manufacturer to improve efficiency and gain competitive advantage.

\subsubsection{Horizontal storage}

\subsubsection{HOMAG Automation TLF}

The TLF storage system is a smart automated horizontal panel storage technology that can work in conjunction with CNC processing machines such as panel saws and can be integrated as part of the production line [29]. An operating staff member is needed to bulk fill the storage and loading area via a crane or forklift. From here the process is automated with the TLF adopting several vacuum cups for grasping and laser sensors to guide angular correction and board size before moving it to its destination Figure 9. A variety of sheet materials such as plastic, glass, laminates and timber panels can be handled without any damage. TLF helps to generate a smoother material flow by connecting with the ordering 
system and planning. Additionally, it can set or read the program schedule and pick orders a night before preparing the production for the next morning. Compared to the traditional multi-level racking storage, HOMAG system enables decrease in floor space by $30 \%$, along with reduced forklift traffic which minimises potential employer injuries [48].

Three models are available for the sheet storage series: TLF 211, TLF 411 and TLF 810; they mainly differ by size and speed to match specific manufactures requirements. As a robust version of TLF 211, TLF 411 provides a larger storage area with travel length up to 50 meters [43]. The higher operation speed leads to a $30 \%$ increase in the pick-up quantity with additional lifting weight of $100 \mathrm{~kg}$ due to the $\mathrm{X}$-shape vacuum plates. TLF 810 provides the largest outspread among the three models with span width up to $21 \mathrm{~m}$. It is suitable for large factories with demand for a variety of materials. A comparison of different capacities among three models is shown in Table 3.

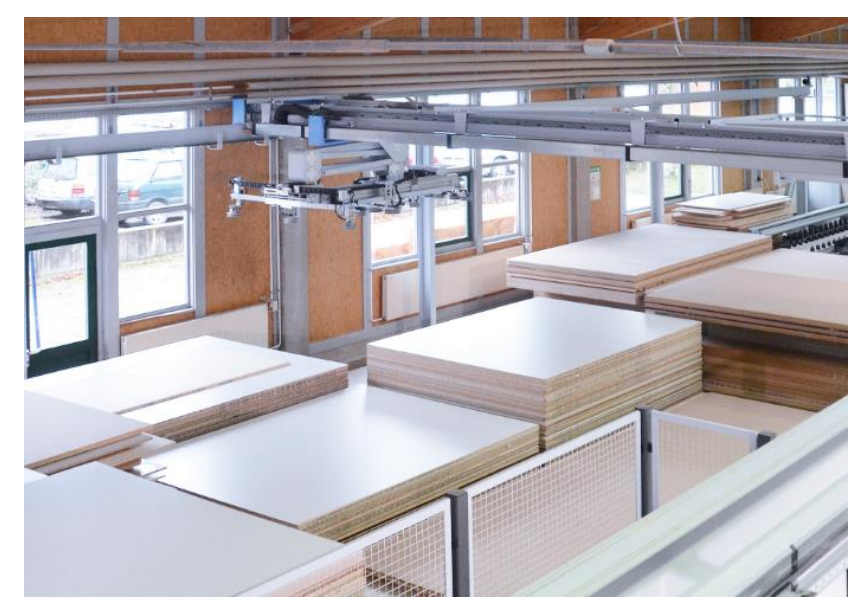

Figure 9. HOMAG TLF 211 storage system [33].

Table 3. Summary of technical data of HOMA TLF storage systems [43].

\begin{tabular}{|c|c|c|c|c|c|}
\hline \multirow{2}{*}{\multicolumn{2}{|c|}{ Technical data }} & \multirow{2}{*}{$\begin{array}{c}\text { Basic } \\
\text { Capability } \\
\text { All models }\end{array}$} & \multicolumn{3}{|c|}{ Improved capability with extra machinery } \\
\hline & & & TLF211 & TLF411 & TLF810 \\
\hline \multicolumn{2}{|c|}{ Span width $(\mathrm{mm})$} & 5,000 & 12,000 & 16,000 & 21,000 \\
\hline \multicolumn{2}{|c|}{ Frame length (mm) } & 10,000 & 50,000 & 50,000 & 50,000 \\
\hline \multirow{3}{*}{$\begin{array}{l}\text { Operation } \\
\text { Speed }\end{array}$} & Bridge $(\mathrm{m} / \mathrm{min})$ & 60 & 110 & 110 & 120 \\
\hline & Carriage (m/min) & 80 & 130 & 130 & 120 \\
\hline & Lifting drive $(\mathrm{m} / \mathrm{min})$ & 30 & 60 & 60 & 90 \\
\hline \multirow[t]{4}{*}{ Board } & Length (mm) & $2,000-4,200$ & Max. 5,600 & Max. 5,600 & Max. 5,600 \\
\hline & Width (mm) & $800-2,200$ & Min. 400 & Min. 400 & Min. 400 \\
\hline & Thickness (mm) & Min. 12 & Min. 3 & Min. 3 & Min. 3 \\
\hline & Weight (kg) & 250 & 250 & 350 & 350 \\
\hline \multicolumn{2}{|c|}{ Stack height (mm) } & 2,100 & 2,500 & 2,500 & 2.500 \\
\hline
\end{tabular}

\subsubsection{Hundegger Pick \& Feed}

The Pick \& Feed system from Hundegger is an automatic handling system to unload packages of timber beams and panels and transfers them to the floor storage area and loading conveyor. Similar to the HOMAG system, the operator needs to manually align the material stack along the loading stop, which 
followed by the automatic pick up and transportation of the package to a free space in the storage. A vacuum technology is also adopted by Hundegger for feeding of timber panels to the panel processing centre such as SPM-2. The CNC control centre can monitor the dimension and position of timber storage, while the single piece construction program enables optimising the material management by prioritizing the panels with cross-sections and lengths required for the project [49].

\subsubsection{CSR}

The storage system for raw materials at CSR is not involved with any automated or smart technology such as barcodes or Radio Frequency Identification (RFID). Stocktake is performed manually and all timber material is moved around by forklift. The loading of material to the production line is purely manual at this stage [28].

\subsubsection{Vertical storage}

\subsubsection{Weinmann WLV/WLW storage technology}

WLV/WLW technology from Weinmann offers a vertical intermediate storing system, allowing panel elements to be easily shifted to the storage and retrieved to be returned to the manufacturing process. The system consists of elements tailored to client's requirements, including swivelling top guide on overhead crane cross rails for automatic element positioning and pick up, loading carriage, standing wall trolley on roller conveyer as well as automatic wall package setup on distribution trolley for transportation. The system is shown in use in Figure 10. WLV/WLW also provides sufficient space that enables finishing work of the panel such as windows and doors fitting and façade installation [30].

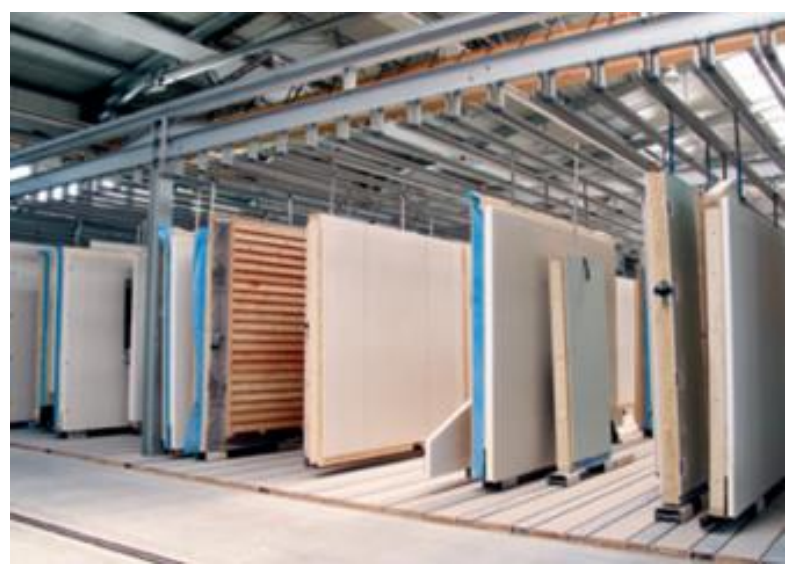

Figure 10. WLV/WLW vertical storgae system [30].

CCG and the biggest timber-frame prefabricated house producer in Poland, DAN-WOOD, are two companies that implement and have proven the WLV/WLW storage technology as part of their production lines. The extensive storage and logistic system is used for vertical storing, picking and loading of wall elements on the distribution trolley. It also enables direct loading of finished products onto the delivery truck, which offers great benefit by significantly reducing the turnaround time [50, $51]$. 


\subsubsection{Randek mobile wall stacker}

The Randek wall stacker consists of roller which allows the finished product to be automatically transported to work stations. From here installation such as window assembly can be performed on the wall element whilst the panel is vertical. The panels are then raised and stacked on a vertical wall rack. After bundling to a package, they are put on a truck and ready for transportation.

\subsection{Buffer station}

The buffer station was originally utilised as a transportation platform that would move elements of the panel from one station to another with dedicated buffer stations absorbing production delays. However, to fully maximise the potential of a buffer table, an assembly line could utilise this station as a transportation and workstation where work checks such as quality assurance or alignment markings would be done. Furthermore, a buffer station will need to be in sync with the adjacent parts of the assembly line layout and therefore may have to be able to able to transport the wall products in 3 directions lengthways, width ways and vertically.

\subsubsection{Randek}

Randek's offers a complete wall manufacturing system and within it the buffer station is utilised for transportation and fastening of the battens to which the wooden cladding will be nailed onto [25]. The transportation speed is pre-set; however, it can also be manually controlled to enable non-damaging start and stop times with high transportation speeds. The system is controlled by chain conveyors providing strength and stability to the station. As the conveyor belt can be stopped, the station can be utilised for manual work or quality checks while production occurs. To further increase the safety of this buffer station, safety mats are included to eliminate the risk that operators might have being stuck in-between two stations [25]. However, this buffer station is only a single directional movement station that moves the components through the manufacturing system lengthways.

\subsubsection{Weinmann}

The Element Table WTW060 is a new development of Weinmann that serves as a multi-purpose buffer station enabling more processes to be done [52]. The elements are transported lengthwise and can be halted at any time manually. Work such as the installation of insulation or the fastening of sheathing can be implemented on the table. This table is relatively small and requires minimum space however the width of the table is adaptable to the width of the wall in the manufacturing line.

\subsubsection{Modular Building Automation (MBA)}

The buffer table supplied by MBA is a multi-directional movement station where timber panels are supported for transportation or work purposes [53]. The panels can be moved lengthwise of width wise. This two-dimensional movement allows panels to be transported around the manufacturing plant easier 
and therefore expands the layout capability of the assembly line as stations can be placed parallel to each other rather than in front of one another.

\subsection{Turning station}

\subsubsection{Butterfly Table: Randek BS40}

A butterfly turning table is a widely used turning process in panelised timber wall prefabrication [26]. Randek butterfly table BS40 is an efficient tool in producing prefabricated walls, roofs and other elements in timber frame as shown in Figure 11. BS40 has two tables and can be used both combined and separately. In a production line, high quality can be checked and ensured due to its clamping function as this function makes sure of the squaring of building components. Meanwhile, the turning process is under an automatic control. BS40 combines 1BS30G upraise working table and BS30N receive work table together. More options can be added as an optional equipment under customer demand.

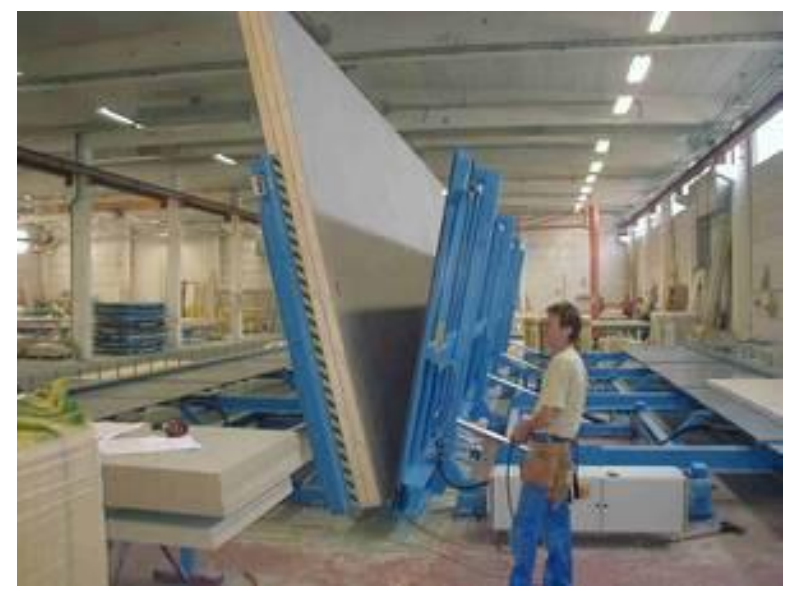

Figure 11. Randek butterfly turning table [7].

\subsubsection{Vacuum Technology: VacuStand VS-180E}

Fezer applies their vacuum technology to turning equipment with the VacuStand VS-180E which can complete a panel turning within 20 seconds on CNC machines. The VacuStand VS-180E contains height adjustment and drives with both side swivel and there is also an adjustment for panels with sandwich elements. The maximum size of the panel is $16 \mathrm{~m}$ long and $1600 \mathrm{~kg}$ in weight [27].

\subsubsection{Turning by a crane}

Turning by a crane is more suitable for many scenarios such as with smaller manufacturing lines that have limited operation area or do not possess a butterfly table. The requisite equipment includes an overhead gantry crane and a free working station. The panel needed to be turned will ideally be placed on a table that enables some level of titling and then lifted by an overhead crane vertically. With help of operators, the panel is turned and placed back to the tilting table. Clearly butterfly tables are a safer and more efficient alternative when it is implemented. 


\subsection{Timber Connections}

The strength of a building relies heavily upon the transfer of load from one connection to another. A solid and reliable connection method must be utilised to increase the strength of timber panel and enable the structure to withhold an excessive amount of stress. In wood buildings, an effective connection will provide the building with strength and ductility [33]. However, there are many connections needed in a wooden structure therefore an economical and durable connection is required to assemble a prefabricated panel quickly and inexpensively in mass production [33].

\subsubsection{Connector Plate}

A simple and affordable connector typically used in walls for joining the horizontal plates is the nail plate. This type of connection is more commonly used as a horizontal connection however can be utilised in a vertical direction if the load is not exceeding the safety limits. Pryda provides a wide variety of nail plates suitable for different structures and loads [54]. The connector plate and knuckle nail plate are galvanised steel connectors with in-built, bent up knuckle nails. They are applied by firmly hammering or pressing the in-built nails into each side of the timber to be connected the latter of which can be automated with a press or roller. Typically, there are 4 columns by 8 rows of in-built nails with an approximate capacity per nail of $280 \mathrm{~N}$ in the parallel direction and $95 \mathrm{~N}$ perpendicular. To increase the load capacity of the connection, holes are present within the nail plate to apply external nails through the nail plate and into the wood.

\subsubsection{Heavy Duty Pre-Punched Plate}

Where a heavier load is required to be supported, a heavy duty pre-punched plate can be utilised. These similar to normal nail plates are made from galvanised stainless-steel plates with multiple holes prepunched through the plate for nails to be driven into. Nails must be driven into every hole in order to maximise the strength provided by this nail plate. There are a variety of sizes and load capacities provided making these plates ideally suited for onsite and offsite construction. These typically range from $75 \mathrm{~mm}$ to $150 \mathrm{~mm}$ wide with maximum tensions and shear from $35 \mathrm{kN}$ and $21 \mathrm{kN}$ up to $70 \mathrm{kN}$ and $42 \mathrm{kN}[54]$.

\subsubsection{Purlin Cleat}

For wall framing connections this consist of a vertical to horizontal connection that can support the load of structures above. The Purlin Cleat is a strong and versatile framing connection as it provides a rigid connection for trusses, rafters and beams to wall plates. This connection is especially suited for concealed applications where the steel material and nails are hidden from view [55]. The connection consists of a 90-degree angle nail plate with pre-punched holes on the top and bottom of each side. Nails are then driven through the holes in the steel plate and into the timber. The purlin cleat should be applied to both sides of the stud, as it will increase the bearing capacity significantly however this makes the process difficult to automate. In structures with high loads, a purlin cleat is mostly used however the installation of this connection is not the most durable, as external nails must be used. 


\subsubsection{Stud Ties}

A simple and durable but low strength connection for framing applications is the tie down connection however the installation of which is generally conducted manually. This type of connection would be useful when building low-rise structures and are easily installed. Specifically, stud ties are a type of tie down connection that consists of a U-shaped nail plate with in-built nails on the top and bottom sections of the steel [54]. These plates are then placed on the top of the frame with the bottom half of the plate into the studs. The inbuilt nails are then nailed into position providing strength and stability to the structure. There are 2 types of stud ties; double sided and single sided, which are typically manufactured. The double-sided stud tie is applied onto both sides of the wooden stud whereas the single sided stud tie is only applied to one side. Because of this the bearing capacity of the double-sided tie is comparatively higher however more cumbersome to achieve in assembly line with flat tables.

\subsubsection{Sherpa Dovetail Connection}

For a balance of durability and strength, a dovetail connection may be preinstalled into both faces of wood. Sherpa connectors provide a wide range of pre-engineered connections, which are quick to install, safe and efficient in construction [34]. This type of connection is prefabricated into the wooden structure where they interlock into place and form a tight fit. The forces are transferred perpendicular to the connection direction and can withstand a large tension force. Two plates, one indented and one protruding outwards, are installed onto the wooden faces of the connection. From there nails are drilled into the sides of the plate at different angles to increase the strength of the connection. During assembly onsite, each wooden panel can then be slotted next to each other through the dovetail quick and efficiently. The dovetail connection is a concealed type of connection where in the case of a fire; it will be protected by layers of wood around the connection. The different types of dovetail connectors are specified in Table 4 with their bearing capacities.

Table 4. Sherpa Dovetail Connection Bearing Capacity [34].

\begin{tabular}{|c|c|c|}
\hline Connector & Screws Required & Bearing Capacity (kN) \\
\hline XS 20 & 25 & 20 \\
\hline S 20 & 25 & 20 \\
\hline M 40 & 30 & 40 \\
\hline L 80 & 29 & 80 \\
\hline XL 250 & 48 & 250 \\
\hline XXL 300 & 59 & 300 \\
\hline
\end{tabular}

\section{Conclusion}

This paper has explored the current and emerging processes within the automated manufacturing of fully prefabricated timber-based walls for panelised buildings. A comprehensive view of the current knowledge and leading industry practice in terms of automation is presented with information sourced from leading automation companies, manufactures, prefabricators and literature were used to fully outline the automation for each respective process. It is evident in the research that certain manufacturing 
processes in timber-based panelised prefabrication are more suitable for automated technologies which is also impacted by the local context. Furthermore, it was clear that a handful of players are leading the automated prefabrication in this area and have progressed in automating many manufacturing processes. It was found that although there are a number of automated technology solutions which are capable of conducting several processes required for timber-based panelised structures, very few offer a fully automated production line for this context. It is recommended that a combination of the most efficient technological solutions for each process to be considered for new or to be upgraded production lines suitable for prefabricated manufacturing of timber-based walls for panelised construction.

\section{Acknowledgements}

The author would like to acknowledge the generous support provided by The University of Melbourne, the Centre for Advanced Manufacturing of Prefabricated Housing (CAMP.H) and the Australian Research Council (Project ID: IC150100023).

ORCID iD: Kristopher Orlowski (D) https://orcid.org/0000-0002-5463-432X

\section{References}

[1] A. Gustafsson and L. Eliasson, "Product quality deficiencies in the prefabrication industry for singlefamily houses," Wood Material Science \& Engineering, vol. 9, no. 1, pp. 1-11, 2014, https://doi.org/10.1080/17480272.2013.847493.

[2] C. Kasperzyk and I. Brilakis, "Automated re-prefabrication system for buildings using robotics," Automation in Construction, vol. 83, pp. 184-195, 2017, https://doi.org/10.1016/j.autcon.2017.08.002.

[3] R. Garay, M. Josu, B. Ayucar and G. Beñat, "Full scale experimental performance assessment of a prefabricated timber panel for the energy retrofitting of multi-rise buildings," Energy Procedia, vol. 122, pp. 3-8, 2017, https://doi.org/10.1016/j.egypro.2017.07.288.

[4] A. Ruuska and T. Häkkinen, "Efficiency in the Delivery of Multi-story Timber Buildings," Energy Procedia, vol. 96, pp. 190-201, 2016, https://doi.org/10.1016/j.egypro.2016.09.120.

[5] P. Zumbrunnen, J. Fovargue and R. Green, "Mid-rise CLT buildings-The UK's experience and potential for Aus and NZ," World Conference on Timber Engineering WCTE, June 2012.

[6] S. Landscheidt and M. Kans, "Automation practices in Wood product industries: lessons learned, current practices and future perspectives," The 7th Swedish Production Symposium SPS, 25-27 October, 2016, Lund, Sweden, p. 9, 2016.

[7] L. Eliasson, "Some aspects on quality requirements of wood for use in the industrial manufacture of single-family timber houses," Linnaeus University Press, 2014.

[8] S. Landscheidt, M. Kans and M. Winroth, "Opportunities for Robotic Automation in Wood Product Industries: The Supplier and System Integrators' Perspective," Procedia Manufacturing, vol. 11, pp. 233240, 2017, https://doi.org/10.1016/j.promfg.2017.07.231.

[9] J. Neelamkavil, "Automation in the Prefab and Modular construction Industry," 26th symposium on construction robotics ISARC, 2009. 
[10] S. Slaughter, "Characteristics of existing construction automation and robotics technologies," Automation in Construction, vol. 6, no. 2, pp. 109-120, 1997, https://doi.org/10.1016/S0926-5805(96)00186-0.

[11] J. Willmann, M. Knauss, T. Bonwetsch, A. Apolinarska and F. Gramazio, "Robotic timber construction — Expanding additive fabrication to new dimensions," Automation in Construction, vol. 61, pp. 16 - 23, 2016, https://doi.org/10.1016/j.autcon.2015.09.011.

[12] K. Henkens, C. Remery and J. Schippers, "Shortages in an ageing labour market: an analysis of employers' behaviour," The International Journal of Human Resource Management, vol. 19, no. 7, pp. 1314-1329, 2008, https://doi.org/10.1080/01446193.2013.787491.

[13] G. Ye, Z. Jin, B. Xia and M. Skitmore, "Analyzing causes for reworks in construction projects in China.," Journal of Management in Engineering, vol. 31, no. 6, 2014, https://doi.org/10.1061/(ASCE)ME.19435479.0000347.

[14] K. Orlowski, P. Mendis and S. Kasun, "Manufacturing, Modeling, Implementation and Evaluation of a Weatherproof Seal for Prefabricated Construction," Buildings, vol. 8, no. 9, p. Article 120, 2018, https://doi.org/10.3390/buildings8090120.

[15] K. Orlowski, S. Kasun and P. Mendis, "Design and Development of Weatherproof Seals for Prefabricated Construction: A Methodological Approach,” Buildings, vol. 8, no. 9, p. Article 117, 2018, https://doi.org/10.3390/buildings8090117.

[16] Hundegger, "Sheet panel saw SPM-2," 2015. [Online]. Available: http://www.hundeggerusa.com/ourmachines/spm-2/. [Accessed 1112 2018].

[17] MBA, "Window assembly table," Modular Building Automation, [Online]. Available: https://www.modularbuildingautomation.eu/window-assembly-table. [Accessed 1512 2018].

[18] MBA, "The complete assembly machine for timber frame panel walls," Modular Building Automation, [Online]. Available: https://www.modularbuildingautomation.eu/mobi-one-timber-frame-assembly. [Accessed 1512 2018].

[19] MBA, "Automatic Timber Frame Assembly Station," Modular Building Automation, 2018. [Online]. Available: https://www.modularbuildingautomation.eu/automatic-timber-frame-assembly. [Accessed 15 12 2018].

[20] Weinmann, "Multifunction Bridge WMS 150 blowTEC," 2 2016. [Online]. Available: http://www.homag.com/fileadmin/product/houseconstruction/brochures/weinmann-multifunction-bridgeWMS-150-blowTEC-english.pdf. [Accessed 1507 2018].

[21] Val-U-Therm, "specifications," 2017. [Online]. Available: http://www.valutherm.co.uk/specifications. [Accessed 2111 2018].

[22] CCG, "CCG Off-Site Manufacturing (OSM)," [Online]. Available: http://c-c-g.co.uk/divisions/off-sitemanufacturing/. [Accessed 0512 2018].

[23] ISLAND Exterior Fabricators, "Prefabrication appoach to facades in buidlings," [Online]. Available: http://www.islandef.com/new-index/\#prefabrication. [Accessed 1507 2018].

[24] S. Gilles, J. Schröer and L. Björn, "Reflective Layer". United States of America Patent US7642948B2, 05 012010.

[25] Randek, “Auto Wall System S3000,” 2016. [Online]. Available:

http://www.randek.com/en/products/wall-floor-and-roof-production-lines/auto-wall-system-s3000.

[Accessed 1311 2018]. 
[26] Randek, "Butterfly table BS40," [Online]. Available: http://www.randek.com/en/products/butterflytables/butterfly-table-bs40. [Accessed 1311 2018].

[27] Fezer, "Turning tables," Albert Fezer Maschinenfabrik GmbH, In den Weiden 26, 73776 Altbach , [Online]. Available: http://fezer.com/turning-tables-vacustand-vs-180e.html. [Accessed 1211 2018].

[28] B. McDonough, Interviewee, Manufacturing process of velocity system from CSR. [Interview]. 752017.

[29] AWISA, "Storage systems shape a new era of manufacturing," AWISA the magazin, vol. 1, no. 25, pp. 36-37, Summer 2015.

[30] Weinmann, "The complete timber work range," 0507 2018. [Online]. Available: http://homaggroupwebapp.homag.de/Medien/WEINMANN_TheCompleteTimberWorkRange_30709.pdf. [Accessed 0507 2018].

[31] F. Harris and R. McCaffe, Modern construction management, London, England: John Wiley \& Sons, 2013.

[32] Y. Sugimori, K. Kusunoki, F. Cho and S. Uchikawa, "Toyota production system and kanban system materialization of just-in-time and respect-for-human system," The International Journal of Production Research, vol. 15, no. 6, pp. 553-564, 1977, https://doi.org/10.1080/00207547708943149.

[33] ReThinkMag, "Connection Options for Wood-Frame and Heavy Timber Buildings," 2014. [Online]. Available: https://www.awc.org/pdf/education/des/ReThinkMag-DES315A1-

ConnectionOptionsForWoodFrameBuildings-1604.pdf. [Accessed 2811 2018].

[34] WoodWorks, "Innovating with Wood," A Case Study Showcasing Four Dimenstration Projects, vol. 1, no. 1, p. 32, 2012.

[35] Weinmann, "Framing station WEM 100/150/250," WEINMANN Holzbausystemtechnik GmbH, 2018. [Online]. Available: http://www.homag.com/fileadmin/product/houseconstruction/brochures/weinmannframing-station-WEM-100-150-250-english.pdf. [Accessed 1711 2018].

[36] Weinmann, "Framing station WEM 100/150/250," 2018. [Online]. Available: https://www.homag.com/fileadmin/product/houseconstruction/brochures/weinmann-framing-stationWEM-100-150-250-english.pdf. [Accessed 2911 2018].

[37] Randek, "Complete System - SF002," [Online]. Available: http://www.randek.com/en/products/wallfloor-and-roof-production-lines/complete-system-sf002. [Accessed 1411 2018].

[38] Weinmann, "Multifunction Bridge WMS 120," 2015. [Online]. Available: http://www.homag.com/en/product-detail/multifunction-bridge-wms-120/. [Accessed 1906 2018].

[39] Randek, "Flexi range," [Online]. Available: http://www.randek.com/images/pdf/flexirange_en_sdspread.pdf. [Accessed 1411 2018].

[40] Strongbuild, "Off-site manufacturing," Strongbuild Australia. 2 - 6 Lexington Drive Bella Vista NSW 2153, 2018. [Online]. Available: http://www.strongbuild.com.au/offsite-manufacturing/. [Accessed 1707 2018].

[41] Soukup, “Assembling table KS2400,” Soukup Komercni 518, CZ 25101 Nupaky, Prague-East, Czech Republic, 2017. [Online]. Available: http://soukup.cz/eshopprodukt/machines_for_window_and_door_production/assembling/assembling_table_ks_2400/en. [Accessed 2807 2018].

[42] Soukup, "Mounting and glazing stand GW2500," Soukup Komercni 518, CZ 25101 Nupaky, PragueEast, Czech Republic, 2017. [Online]. Available: http://soukup.cz/eshop- 
produkt/machines_for_window_and_door_production/assembling/mounting_and_glazing_sand_zs_2700z/en. [Accessed 2807 2018].

[43] HOMAG Automation, "Storage Technology - The perfect solution for an efficient production," [Online]. Available: http://www.homag.com/fileadmin/product/automation/brochures/HOMAG-AutomationProspekt-Lagertechnik-EN.pdf. [Accessed 1412 2018].

[44] Scotframe, "Introducing Scotframe's unique family of advanced, closed panel, factory insulated, high thermal performance wall, roof and floor systems," Scotframe, Inverurie Business Park, Souterford Ave, Inverurie AB51 0ZJ, United Kingdom, 2015. [Online]. Available:

http://www.scotframe.co.uk/MainlandUK/Val-U-Therm/Scotframe-Val-U-Therm.aspx. [Accessed 0210 2018].

[45] Randek, “Auto Wall System S3000,” [Online]. Available: http://www.randek.com/en/products/wall-floorand-roof-production-lines/auto-wall-system-s3000. [Accessed 1311 2018].

[46] CSR, "CSR Velocity system. A leading building products company in Australia and New Zealand.," [Online]. Available: https://www.csr.com.au/building-solutions/offsite-and-prefab/csr-velocity-system. [Accessed 0506 2018].

[47] HOLZMA, "HPP 300 multiTec - sawing, drilling, routing," [Online]. Available: http://www.homag.com/fileadmin/product/paneldividing/brochures/panelsaw-multiTec.pdf. [Accessed 29 $112018]$.

[48] Stiles, "Homag Automation IntelliStore," HOMAG GmbH, 2018. [Online]. Available: https://www.stilesmachinery.com/HOMAGautomation/intellistore\#tab-1. [Accessed 29112018 ].

[49] Hundegger, "Handling system: Pick \& Feed and Pick \& Place," Hans Hundegger AG, Kemptener Str. 1,D-87749 Hawangen, Germany, 2018. [Online]. Available: https://www.hundegger.de/en/machinebuilding/products/pick-feed-and-pick-place.html. [Accessed 212 2018].

[50] Homag, "High degree of prefabrication allows for top-quality timber frame construction," 2016. [Online]. Available: http://www.homag.com/fileadmin/customers/CCG-prefabrication.pdf. [Accessed 1109 2018].

[51] Homag, "In the fast lane - Polish prefab manufacturer takes off," 2016. [Online]. Available: http://www.homag.com/fileadmin/customers/Danwood-assemblytabble.pdf. [Accessed 0509 2018].

[52] Weinmann, "Weinmann Treff Automation," WEINMANN Holzbausystemtechnik GmbH, 2016. [Online]. Available: https://www.homag.com/en/nc/news-events/case-studies/. [Accessed 16102018 ].

[53] MBA, "Buffer Station," Modular Building Automation, 2016. [Online]. Available: https://www.modularbuildingautomation.eu/buffer-station. [Accessed 1512 2018].

[54] Pryda, "Pryda Timber Connectors," 2016. [Online]. Available: http://www.pryda.com.au/wpcontent/uploads/2016/05/Connectors-and-Tie-Down-Guide-MARCH-2012.pdf. [Accessed 1210 2018].

[55] Pryda, "Pryda Timber Connections," 2016. [Online]. Available: http://www.pryda.com.au/wpcontent/uploads/2016/05/Timber-Connectors-Catalogue-FEB2016.pdf. [Accessed 1210 2018].

[56] R. Salim and J. Johansson, “Automation decisions in investment projects: A study in the Swedish wood products industry," Procedia Manufacturing, vol. 25, pp. 255-262, 2018, https://doi.org/10.1016/j.promfg.2018.06.081. 